\title{
How benchmarking motivates farmers to improve dairy calf management
}

\author{
Christine L. Sumner, Marina A. G. von Keyserlingk, and Daniel M. Weary ${ }^{1}$ \\ Animal Welfare Program, University of British Columbia, 248-2357 Main Mall, Vancouver, BC V6T 1Z4, Canada
}

\begin{abstract}
Dairy calves often receive inadequate colostrum for successful transfer of passive immunity and inadequate milk to achieve their potential for growth and avoid hunger, but little is known about what motivates farmers to improve calf management around these concerns. Our aim was to assess if and how access to benchmarking reports, providing data on calf performance and peer comparison, would change the ways in which farmers think about calves and their management. During our study, 18 dairy farmers in the lower Fraser Valley (British Columbia, Canada) each received 2 benchmark reports that conveyed information on transfer of immunity and calf growth for their own calves and for other farms in the region. Farmers were interviewed before and after receiving their benchmarking reports to gain an understanding of how they perceived access to information in the reports. We conducted qualitative analysis to identify major themes. Respondents generally saw having access to these data and peer comparisons favorably, in part because the reports provided evidence of how their calves were performing. Benchmarking encouraged farmers to make changes in their calf management by identifying areas needing attention and promoting discussion about best practices. We conclude that some management problems can be addressed by providing farmers better access to data that they can use to judge their success and inform changes.
\end{abstract}

Key words: animal welfare, extension, theory of planned behavior, attitude

\section{INTRODUCTION}

Understanding the role of information in identifying and improving management on farms is a key area of interest in animal welfare research. Research aimed at adoption of practices to reduce welfare risks on farms has indicated that a lack of information is a barrier.

Received July 29, 2017.

Accepted January 5, 2018.

${ }^{1}$ Corresponding author: danweary@mail.ubc.ca
For instance, Leach et al. (2010a) reported that welfare problems such as lameness are more likely to persist on dairy farms when farmers underestimate the extent of the problem within their herd. Similarly, Becker et al. (2013) found that farmers could underestimate the severity of pain in treating foot problems because they lack an understanding of how to assess pain in cows.

Dairy calves face several risks in the early weeks of their lives, including inadequate colostrum for transfer of passive immunity (Windeyer et al., 2014), and inadequate milk to achieve their potential for growth and avoid hunger (reviewed by Khan et al., 2011). The technical solutions to these problems are well known; what lacks is an understanding of the factors that limit adoption of these solutions on farms. Specifically, there is a lack of research on how farmers view these concerns and what motivates them to make decisions when it comes to managing their calves. Increasing farmer awareness and education on health-related practices, such as colostrum management, may encourage improvement in welfare outcomes for calves (Heinrichs and Kiernan, 1994; Kehoe et al., 2007; Beam et al., 2009). The provision of information can influence a person's attitude and behavior toward a phenomenon (as reviewed by Glasman and Albarracín, 2006). In addition to attitudes, understanding a person's beliefs about who may influence their decision-making and how much control they have in making decisions are key factors in understanding a person's motivation (Ajzen, 1991).

One way of providing information is through benchmarking. Benchmarking is the process of measuring performance using specific indicators and then comparing performance with that of peers with the intention of improving on those indicators (Fong et al., 1998). The key concept is to use data to identify performance gaps and drive improvements. Although often used to increase efficiency (Anderson and McAdam, 2004), benchmarking can also be used to motivate changes not directly linked with economic outcomes (Magd and Curry, 2003).

A previous study from our group evaluated benchmarking to improve lameness outcomes for mature dairy cows (Chapinal et al., 2013), but that study was retrospective, did not include controls, and assessed 
only biological outcomes (e.g., lameness). Another study compared calf mortality on 2 farms and suggested that the comparison of the underperformer with a high performer helped identify management and employee training not previously thought as pertinent to calf mortality (Khade and Metlen, 1996). In a companion paper to the current study (Atkinson et al., 2017), we showed how benchmarking calf growth and transfer of immunity resulted in some farms changing their management in ways that improved outcomes related to both measures. To our knowledge, no previous work has assessed the effect of benchmarking on farmer perceptions toward their animals and their motivation to improve.

The aim of the current study was to describe how benchmarking motivates farmers to make changes in calf management. We used a qualitative, interview-based approach to assess how access to benchmarking reports, providing data on transfer of immunity and growth, would change the ways in which farmers thought about calves and making changes in their management.

\section{MATERIALS AND METHODS}

This study was approved by the University of British Columbia Behavioral Research Ethics Board under \# H14-03196. All participants provided written consent.

\section{Study Design}

This interview study was designed from a critical realist perspective that emphasized understanding the meaning that people attach to a phenomenon and the context within which this occurs (Manicas, 2006; Maxwell, 2012). For the current study, we were interested in understanding the phenomenon of farmer perspectives about factors related to the benchmarking process that motivated them to make changes in calf management, the specific context of our intervention study. Following the framework of Maxwell (2012), this approach allowed us to identify mechanisms within the situation (i.e., the benchmarking study) that cause a particular outcome (i.e., why farmers made changes). Specifically, we were interested in describing the mechanism(s) of change that motivated farmers to improve calf management based on the provision of information in the benchmark reports about their calves and those of their peers participating in the study.

We purposively recruited from 18 commercial dairy farms in the lower Fraser Valley of British Columbia that participated in a benchmark study (see Atkinson et al., 2017 for details concerning recruitment, biological measures and outcomes, and report delivery). We interviewed individuals responsible for calf care, includ- ing farm owners, herd managers, and calf managers. Choosing these individuals allowed us to fulfill 2 criteria with sampling consistent with Maxwell (2012): (1) they can best help us answer our research question because they participated in the benchmark study, and (2) they were the individuals who could best speak about the calf management on each farm.

During the study, each farm received 2 reports 10 wk apart. These reports described serum total protein from calf blood samples and average daily gains (as estimated from heart-girth tapings) and information on management practices on all study farms. Reports provided data on the individual calves and graphically presented data to facilitate interpretation. Each report was presented by the herd veterinarian who used examples of other study findings (e.g., on the effects of increasing milk ration on calf growth) and props (e.g., a colostrometer for testing colostrum quality) to facilitate the discussion. Examples of the content found in these reports can be found at https://figshare.com/s/ 7af49a9205a47ceb1363.

\section{Interview Guide, Data Collection, and Participants}

We used the theory of planned behavior to develop the interview guide for semi-structured interviews. The theory of planned behavior constructs (attitudes, subjective norms, and perceived behavioral control) are key to understanding a person's motivation to perform a behavior (Ajzen, 1991). According to the theory of planned behavior, "attitudes" are positive or negative evaluations of a behavior, "subjective norms" are the perceived social expectation toward performing a behavior, and "perceived behavioral control" refers to perceived ease or difficulty toward performing a behavior (Ajzen, 1991). The theory of planned behavior has been used as a framework to provide structure for open-ended qualitative inquiries (Goh, 2009; Borges et al., 2014), including with dairy farmers and decisionmaking (Hötzel and Sneddon, 2013; Brennan et al., 2016). For our study, we developed questions for interviews that occurred before and after farmers received their benchmark reports. During the initial interviews, we asked farmers a series of open-ended questions and follow-up probes about calf management (How do you think your calf management is going?), how they felt about making decisions about their calves (How easy or difficult is it for you to make decisions about how you manage your calves?), how they felt about collecting data on their calves (Can you tell me about benefits or challenges you think there are with collecting data on your calves?), and how they felt about comparing their own farm performance against their peers (Who influences the way you manage your calves?). Farmers were 
also asked questions about the priority given to calves on the farm in general (What priority are calves given on your farm?). In the subsequent interviews, after receiving 2 benchmark reports, we asked farmers the same questions from the first interviews, but adjusted the wording with respect to farmers now having access to data on their calves and peer comparison. We also asked farmers for any additional thoughts on the topic.

The first round of interviews took place before delivery of the first benchmark report on all 18 farms, with 21 people interviewed. We conducted follow-up interviews after farms had received their second benchmark report on 16 of the 18 farms, interviewing a total of 19 people ( 2 farms were not included in the second round of interviews due to scheduling conflicts). When a farm had multiple interviewees, they agreed to be interviewed together. Interviews were audiotaped and conducted by the first author on the participants' own farms.

\section{Data Analyses}

Interviews were professionally transcribed and transcripts were compared with the original audio files to ensure fidelity. We used Nvivo (version 10.2.2; QSR International, Burlington, MA) for data analysis. We treated the participants as a single case bound by context (participating in the calf benchmark study and geographic location) and conducted a within-case analysis using a variable-oriented approach based on a priori theoretical constructs of the theory of planned behavior (Ajzen, 1991) and inductive analysis. Consistent with a within-case approach, all farmers were treated as a single entity rather than using comparison among farmers. This approach allowed us to identify major themes that arose based on identifying phenomena related to the variables of interest and the patterns that emerged between these phenomena (Miles et al., 2014).

We analyzed interview data using a 2-step coding process: the first step involved condensing the raw data into groupings (codes) and the second step condensed these groupings into "more meaningful and parsimonious units of analysis" (categories; based on Miles et al., 2014, p. 86). During the first step, data were organized using an a priori list of codes based on the theory of planned behavior constructs (attitudes, social norms, and perceived behavioral control) and a code for "values." This was followed by the development of more specific codes to further distinguish the different topics that emerged during the analysis. For example, data classified under the "attitudes" code were separated into attitudes about calf management and attitudes about benchmarking. The lead author and another trained individual developed a list of code definitions that were then used to code a subset of the interviews; discrepancies on how data were coded were discussed until consensus was reached. The lead author then coded the remaining interviews. During the second step of the analysis, sections of the transcripts labeled with more than one code were further organized into categories based on the relationship between the overlapping codes. These categories were then organized into the 3 major themes reported in the Results section of this paper. Quotes were selected to represent examples of a given category within each theme; we specifically identified statements reflective of many responses and that more clearly expressed a given concept. Quotes have been modified for length and clarity: ellipses indicate where text was omitted to reduce quote length, and brackets indicate the authors' additions to the text.

\section{Validity}

To stay consistent with our critical realist approach, we used a framework that organizes concepts based on descriptive validity (what is reported as seen and heard), interpretive validity (the participant's perspective), and theoretical validity (meaning is explained through concepts and their relation; Maxwell, 2012). For concerns about the descriptive validity of our study, we relied on audio recordings of all interviews and checked all transcripts against the original recordings. For concerns about the interpretive validity, the lead author and sole interviewer made repeat visits to the farms for interviews and report meetings to establish rapport with the participants, employed repeat interviews that helped confirm respondents' answers to questions, used multiple researchers to analyze the data to minimize researcher bias, and maintained an ongoing log of notes documenting the research process. For concerns with theoretical validity, we used an established theory to frame our data collection and analysis, and we used an analytic framework to develop our themes (from codes to categories, and finally themes) based on Miles et al. (2014).

\section{RESULTS}

Three major themes emerged during data analysis, explaining how providing information about calf performance and peer comparison in benchmark reports influenced farmer decision-making. Collectively, the responses suggest that benchmarking motivated farmers to improve calf management because of the intrinsic and instrumental value of having access to data and peer comparisons. Additionally, farmers' values about their calves emerged as a key feature in how access to data and peer comparison motivated them to im- 
prove calf management. Finally, benchmarking calf management shifted the social norms among farmers around calf management. Our study design was based on interviews before and after farmers received their benchmark reports. The themes are organized to show farmers' perceptions of their calves, their calf management, and their peers before and after they had access to data on their calves and peer comparison.

\section{Theme 1: Improved Farmer Confidence from Access to Data and Peer Comparison}

Access to data on their calves and peer comparison had intrinsic value (i.e., value in itself) for farmers because it instilled a sense of confidence in their assessment of their calves and calf management. Before access to the benchmark reports, farmers' perceptions of success were based on methods of assessment that did not rely on data. Once farmers received their benchmark data, reports improved their confidence because it provided an additional measure of success.

Before Benchmark Reports. During the first set of interviews, before recurring benchmark reports, farmers expressed both confidence and ambivalence about managing their calves. Farmers described a range of factors related to confidence in their ability to manage calves. For example, low mortality for preweaned calves was perceived as an indicator of success, "I think it's going excellent right now... There's very little calf loss" (Farmer 15). Another outcome of success was breeding age for heifers. For example, when describing why they felt their calf program was going well, the following 2 participants (both from Farm 4) included breeding milestones and growth, "We're able to raise our calves bigger, quicker" (Farmer 4A) and, "We were breeding them [heifers] at 13 months; we've changed a couple little things, now we're breeding them at 12 months" (Farmer 4B).

Confidence in successful calf management also included the ability to identify sick calves based on visual assessment. Farmers relied on a range of behavioral indicators to assess the health of their calves. Farmer 5 described his observations as follows, "... if the calf's not drinking or slow-drinking, just look if it's got a bit of a snotty nose or droopy ears or it's got scours. It's usually maybe a touch of pneumonia ... And [it is] just usually those two things, if you assess that pretty quick, I don't think we lose a calf a year."

Activities related to calf management were also linked to confidence, including the use of vaccine schedules, hygiene protocols, and colostrum management. For example, when describing how well his calves were doing, Farmer 1 reported, "I think we've thought it out pretty well. We do a good job with cleanliness and tidiness, capitalizing on things that need to be capitalized on."

We also noted a degree of ambivalence about assessing and managing calves, often based upon the lack of relevant data to support assessments. For example, Farmer 11 commented on the lack of data for assessing failure of passive transfer of immunity, "I never had my calves tested ... So, have I had problems with sick calves before? Yes. Have I pinpointed it to my colostrum management? No. So, to say that, I don't really know if I've had problems with my colostrum management before ... Kind of been like, 'we're okay'. But have I had a lot of research to back up that 'think we're okay,' no." Having data on calves was anticipated to address ambivalence. Farmer 13 indicated the value of data in providing reassurance, "... it would just be a good relief to know you're raising good heifers."

Ambivalence was also expressed in terms of questioning routine practices that were not supported with relevant data. Farmer 10 expressed mixed feelings about the quality of colostrum fed to calves, given that quality was not tested. He stated, "If I have a healthy cow through a healthy transition period that had a healthy far-off period, [she] should have a healthy first, second feeding for its baby. And I just trust that. Should I trust that? Well that's probably just me with my blinders on."

The anticipated value in having data on their calves was linked with personal values farmers expressed. For example, Farmer 11 described the value of having data on his calves in relation to identity, "I want to be a good farmer ... I want to do well at everything I do, so if I see a benchmark that I'm not doing well, then I want to figure out a way within economic reason to do a better job ... if I can change little things to do better, then I absolutely will do that." The calf's intrinsic value was also linked with an anticipated value in collecting data. Farmer 10 explained the link between using data to improve calf management and the value placed on the calf, "... it's a living, breathing animal in my care ... That's why I do the best I can at the beginning."

After Benchmark Reports. Once the participants received their benchmark reports, access to data on calves was either confirmatory or surprising for participants. For example, Farmer 1 commented how the report validated his perceptions regarding calf growth, "... I'd already noticed ... just visually and on a dayto-day basis ... They're just bigger, healthier, stronger looking calves ... it being on paper, obviously, it seals the deal." The influence of the peer comparison had similar effects on the farmers' perceptions. Farmer 17 described the peer comparison as beneficial because, "... it just gave you confidence that you're doing something right." Comparing calf outcomes gave farmers a reference point 
for interpreting their own performance. As explained by Farmer 15, "... your numbers aren't that valuable if you don't have anything to put it against." Peer comparison also motivated farmers based on a sense of pride in doing well. As Farmer 12 explained, "I guess it put a little bit of a level of competition. Maybe a little spark under your butt to make sure what you're doing - knowing where I am ... keep it up or try to improve a little bit ... You don't want to be on the bottom end of the scale ... there is a sense of pride to be on the higher end of that."

In some cases, information in the benchmark reports came as a surprise to farmers and challenged perceptions about their calves. Despite this surprise, a favorable view of the information emerged. For example, Farmer 5 explained the benefit of having data to estimate immunoglobulin transfer from colostrum, "Well, you know, the first round surprised me, the low [blood serum levels] ... I think it [the blood serum data] was definitely advantageous ... I think it was very good, especially the colostrum thing was a good eye opener." This favorable view of information was echoed when describing the influence of peer comparison when farmers' perception of their own performance did not align with expectations. Farmer 13 described his assessment of his own calves in relation to those on other farms, "... we thought the calves were doing better than what they were ... so after the first report [when] we got all that data, it was, like, 'okay, there's other farms doing better. And we're doing pretty good but we could be doing better'."

In some cases, making changes based on access to data in the first report led to the expectation that there would be improvements, and this led to a sense of ambivalence if these were unrealized following the delivery of the second report. As indicated by Farmer 6 when he failed to see improved growth after increasing milk allowance for his calves based on recommendations from the benchmarking study, "... I just didn't see the results that I thought I would see."

Reports instilled a sense of ambivalence when they conveyed inconsistent findings. Farmer 15 discussed the data regarding colostrum management, "I was surprised the second time we were low on [blood serum levels]. But I was overly surprised the first time on how well we had done on colostrum. Which was the fluke? I don't know."

\section{Theme 2: The Instrumental Value of Access to Data and Peer Comparison}

Access to data and peer comparison also had instrumental value (i.e., value as a process) for farmers because it provided them with examples of ways to address problems on their farm and showed that improved outcomes were achievable. Before receiving their reports, farmers anticipated using the data to improve calf management practices. Once they had their reports, farmers used them to inform their decisionmaking.

Before Benchmark Reports. Before receiving the benchmark reports, the participants conveyed their anticipation on how the data would enhance calf management. In the words of Farmer 18, having data on calves was a learning opportunity, "Well, I think if you monitor something you can learn something and if you can learn something you can do something better." Farmer 13 commented specifically about the value of these data for monitoring calf growth and milk feeding decisions, "Well, I think it's a great benefit. First of all, to see how your calves are growing, if there's room for improvement. You know if you've got to feed them more aggressively ..."

The anticipated value of the data was linked with the calf's future role as a productive cow as referenced by Farmer 12, "... I do see the value. Well, they're the future of the herd. My goal is to get a really young herd, so that's where we're headed." Farmer 10 explicitly linked collecting data on calves with the duality of his own welfare and that of his calves, "I'm very curious by nature. I've got to know everything that I don't know. And I think that's what makes me a stand above farmer ... I'm either bettering the cows and my calves for my benefit, or for theirs."

Farmers also discussed how making management changes required some consensus with others working on the farm and, before receiving their benchmark reports, farmers discussed this challenge. For example, Farmer 10 described the difficulty of working with others who have different management priorities, "... it can be a little difficult to get everybody else on board because ... they're not really cow people, they're equipment people ..." At other times, determining how to approach others for support in making changes in management was a challenge. Farmer 15 described learning how to best approach a family member to increase the likelihood of acceptance, "In some ways we were butting heads about different things, and then I kind of would just start saying little things here and there ... and he would eventually think these ideas were all his own ..."

When farmers discussed benchmarking calf management, they linked the process of peer comparison with usefulness of knowing what other farmers are doing. As Farmer 12 explained, an anticipated benefit to benchmarking was broadening horizons about their own performance, "because if you don't [benchmark]-especially if you've got your head in your own farm, you never leave your yard, you don't know ... But it could be that much better... you find out your neighbor is doing it 
that way, and he's getting much more out of something ..." For others, the value of benchmarking was that it connected them to other farms for the purposes of identifying practices that may be beneficial. Farmer 16 explained the value in comparing peers on calf growth, "If you know your calves are not heavy enough or they are not calving in at a proper height ... it gives me an idea of what ... other people are doing, and where I stand."

At times, the anonymity of the benchmark process was problematic for farmers when they anticipated comparing their performance with their peers and in relation to the feasibility of adopting particular practices on their own farms. This limitation was evident in participant concerns about the benefits of making changes based on how other farmers manage their calves. As Farmer 5 explained, "... we don't know who we're up against ... in business, sometimes that's the most important thing, is not to chase something you don't know about."

Concerns about adjusting management systems to include data collection were also expressed. These concerns were related to the type of indicator measured and means of data capture. For example, Farmer 4 explained, "... you got to collect data ... you got to record data ... majority of farmers aren't pencil pushers, you know, so you need a system that's relatively easy and something that farmers are going to keep up."

After Benchmark Reports. Once farmers had access to the data in their benchmark reports, they tended to use this to identify aspects of calf management that needed attention and thus could better focus their efforts. This increased their sense of having control over the outcomes.

With access to data on their calves, farmers identified deficits in calf management that enabled improvements. For example, Farmer 16 explained how data on passive transfer of immunity helped him notice problems in colostrum management, "I was going through it the benchmark report] ... saw the times that I was away and the times that I was around, because I was interested to see what the change would be. And that's [where it] was noticeable. So, I learned something there right away ... it was a pattern ... it's one of those things that you find a hole in your program and it gives you the ability to patch it up ... and having this study really helped."

Having access to data also allowed farmers to better link calf outcomes with managerial and environmental features. For example, Farmer 15 used the report to evaluate specific environmental factors affecting calf performance: "it did help me reflect upon [that] certain pens grow better, certain spots in the calf shack ... we don't use some pens now because of that." Benchmarking also helped shift expectations of what could happen when making changes in calf management. Farmer 7 explained how benchmarking changed her outlook on increasing milk allowance for the calves, "... we knew there were problems here, but it was just kind of 'that's always how it had been'... nobody really thought of thinking outside the box of how we could improve this. Because before ... if you feed too much milk, they're going to get sick and die and that's just kind of the mentality [of] how it is, you're in a rut and you just think it's normal. But now you can see like, 'wow, like no, that's not normal'."

Having the ability to make changes based on access to data also provided an opportunity for farmers to address concerns that they had not yet acted upon. Farmer 10 described making changes related to calf nutrition, "... things that maybe were in the back of my head, that maybe we should be doing this or not. Giving water right off the bat, free choice. I didn't think a calf needed water. But in my head I'm thinking, 'well, I've always wondered at seven days old when it's $30^{\circ}$ out, would it want water? Would it drink it?"

Once farmers received their benchmark reports, they often used these data to negotiate changes in practice with others on the farm. The data were used to persuade others that the changes made were beneficial, or that further changes were now required. In making changes because of poor performance, Farmer 7 described the process of instituting change with subordinates, "... we sat down with [the calf feeders, and said,] 'we got problems here, calves used to be the bottom priority, now they're the top priority ... do the calves first and do them properly first." For others, access to data facilitated navigating intergenerational conflict, as the data supported their efforts to enact change and strengthened their role as a decision-maker. For example, Farmer 14 used the reports to help convince a family member that increased milk allowance would be beneficial, " $I$ knew that we had to make some improvements with our newborn calf care ... when you're working with someone who's very old school in his approach, you need to kind of have some backup to it. And it [benchmark data] helped ... it helped change his focus."

Peer comparison provided a reference to gauge if changes were required. As Farmer 15 indicated, "... We saw other people that were doing worse, but we saw also people that were doing better ... although we haven't been on everybody else's farms, we feel like we do a pretty good job of everything, so we should be able to get that gain that they're getting."

Peer comparison had less value if participants believed that the performance differences were related to different strategies at work on the different farms. For Farmer 11, perceived differences in goals related to calf growth limited the usefulness of peer comparison, "... 
Our heifers are bred at a year old. They're bred young, and they're all going to calve these small calves ... it's on purpose ... They have to be taken care of a little bit differently than guys who have these monster cows... If all your calves are like that, then your numbers are going to be, like, 'oh wow, this guy's an amazing farmer.' It's, like, 'yeah, because he's got big calves'..."

For other farmers, calf performance had to be seen within the limitations for that farm. As Farmer 8 explained, "... people are given different resources ... you have to kind of work within your constraints and try and make the best animal that you can make."

\section{Theme 3: Benchmarking and Shifting the Social Norms Around Managing Calves}

Access to data and peer performance on calves helped shift the social norms associated with calf management. Before receiving benchmark reports, farmers indicated that calf management was not typically discussed among farmers. Access to data and peer performance encouraged a shift toward calf management as a topic for farmers to include in their interactions with other farmers.

Before Benchmark Reports. A range of reasons emerged for why calf management was not commonly discussed among farmers. For Farmer 7, discussing calves with other farmers rested on the perception of problems with calf management, "If you had problems with your calves, it would be a more common topic ... if I had a lot of problems, then I guarantee it would be more of a topic of conversation."

For Farmer 11, linking calf feeding and childhood tasks contributed to calves not being commonly discussed, "Because it's something that everyone's always done ... everyone's always remembered doing it as a little kid so it's just always something, a simple thing, even though it's not really ... But there's a lot more to it that we just don't really talk about."

Autonomy was also expressed in relation to how farmers viewed peer comparisons. As Farmer 5 explained, "I'm not saying I don't value what other producers do ... it might work really well for them, but to make it work, you might have to change everything. So everyone's got to work with what they have and the systems and the barns they have ... you have to run your own programs."

Distinguishing oneself as progressive in adopting new management practices was also expressed in relation to peer comparison. As Farmer 4 explained when describing the value in collecting data on calves, doing what was best was linked with doing things differently from previous generations, "We're the younger generation right. The younger generation always wants to change things quicker. The older guys keep things the same ... We're always going to try something that's a little bit more maintenance but better for the calf."

After Access to Benchmark Reports. After receiving their reports, how much farmers reported the influence of other farmers varied. For some, a lack of influence from other farmers after receiving data comparing farms was linked with a lack of discussing calves in general. As Farmer 3 explained, "Well, to be honest with you, I probably never talk to anybody about calves." For others, such as Farmer 17, the peer comparison prompted minor change, "There's a couple of other farms that we knew that were on the study and [we] kind of compared notes a little bit." Others, such as Farmer 13 , saw this influence in context with the specific requirements of his own farm, "I think for us the changes that we made [with feeding milk] ... some producers were doing that. And there's evidence out there supporting that [feeding more milk] does help the growth, so that's what we basically made the decision on." Some farmers purposely tapped into existing social networks to discuss specific changes to calf management such as increasing the amount of milk fed to their calves. Farmer 11 offered, "Well, I talked to one farmer down the road ... and he went through the same study ... I've asked him questions about certain things ... he's the one ... that told us ... they feed three times a day." For other farmers, such as Farmer 1, discussing calves with other farmers was a benefit, "It's good to circulate ideas with other farmers ... I think it's definitely a good idea to get together or talk about it or compare ideas or systems that they're actually running on their farm ..."

\section{DISCUSSION}

Researchers have used the theory of planned behavior to understand how farmers intend to address dairy cattle lameness (Bruijnis et al., 2013) and disease prevention (Brennan et al., 2016), sow housing (de Lauwere et al., 2012), and animal welfare in general (Kauppinen et al., 2010). Apart from Brennan et al. (2016), these studies used this theory to quantify farmers' intentions to behave. In the current study, the theory of planned behavior provided structure for developing the interview guide and during the initial stages of data analyses. We modified our approach in accordance with Bruijnis et al. (2013) and included topics of values in the data collection and analysis phases. This approach provided additional insights into the complexities of farmer decision-making (Burton, 2004). Critiques of focusing on correcting knowledge deficits to address on-farm problems have suggested that a more nuanced approach is needed (Kristensen and Jakobsen, 2011). Our study contributes to this approach, illustrating 
how motivation to improve calf management is associated with access to information and peer comparisons and the value farmers placed on their calves.

The benchmarking process provided farmers with information on how their calves were doing and on how they compared with other farms, challenging them to rethink their calf management. In his work on benchmarking theory, Moriarty (2011) described a process of learning about "the state of affairs" as a critical component of a benchmark because it provides participants with an understanding of their own operations. In our study, seeing their own data in relation to other farms was linked to farmers' feelings of confidence in knowing how well they were managing their calves. De Lauwere et al. (2012) reported that confidence in good outcomes was a key difference between farmers who made welfare-focused changes in sow housing compared with farmers who made no changes. Vaarst and Sørensen (2009) identified confidence in managing calf mortality as being crucial to farmers reporting a sense of control over their ability to manage future problems.

The ambivalence noted by some of the farmers in how they felt about calf management was linked with being unsure about their assessments before receiving reports and inconsistencies between the reports causing a sense of confusion. Te Velde et al. (2002) suggested that farmers' sense of ambivalence toward their animals is addressed through coping mechanisms that ultimately justify maintaining the status quo. This does not explain our findings; ambivalence was not linked with defending the status quo but rather introspection regarding their own calves. Moreover, feelings of ambivalence are to be expected when farmers received conflicting reports, as they could not verify the effectiveness of their management. Farmers may have benefited from an ongoing process with multiple reporting periods, allowing them to assess the consistency of their results.

Attitudes toward using data from benchmarking were mostly positive before and after receiving the reports. Brennan et al. (2016) noted that dairy farmers were motivated to improve disease status on their farms once they became aware of a problem. Similarly, Jansen et al. (2009) noted that farmers acted to improve mastitis once they considered it a problem. The results presented in our companion paper (Atkinson et al., 2017) showed that farmers made changes to their calf management when they became aware of issues following delivery of the benchmark reports. Here, we have described how farmers specifically commented on their ability to use data to inform decision-making. They described a process of refinement, targeting specific parts of their calf management based on the data identifying where issues existed.
Perceived behavioral control is important in motivating behavior (Armitage and Connor, 2001). We suggest that perceived behavioral control explains how the provision of data motivated farmers to improve management. For instance, farmers anticipated using the data to improve calf management practices (before benchmark reports), and again referred to it when they described the changes they made after the reports were delivered. This sense of anticipating and experiencing positive outcomes associated with access to data was also present when farmers discussed navigating changes with family members and staff. Others have also described the importance of control. Vaarst and Sørensen (2009) reported that on dairy farms with low calf mortality, perceptions of control were linked with a perceived ability to make appropriate decisions with regards to calf health. Farmers likely feel empowered when they can make informed decisions that target problems with a solution.

In our study, farmers expressed a range of values attached to their calves. They placed instrumental value on them as future members in the lactating herd and inherent value on them as living beings. They also linked their calves' welfare with their own identity as a good farmer. Our study provides some indication that the perceived value of benchmarking as a tool to improve management is associated with the values that farmers attach to calves and with their identity as a farmer. This more robust view of decision-making has been noted in other studies (Burton, 2004; Kristensen and Jakobsen, 2011; de Lauwere et al., 2012). Kauppinen et al. (2010) found that instrumental and intrinsic values of animals were not mutually exclusive, a finding also reflected in the current study. Farmers held multiple values regarding their calves and, consistent with other studies (e.g., Leach et al., 2010b), did not limit their decisions about improving calf management to economics.

Before benchmarking, calves appeared to be a low priority topic for discussions with other farmers. Jansen et al. (2010) found that how farmers feel about turning to fellow farmers for information was linked with the degree of trust they put in information from external sources. What may be the best explanation of the reported lack of influence of other farmers is the recurring expression of autonomy in managing a farm. Burton (2004) has argued that underestimation of the influence of other farmers is related to the independence characteristic of farming.

After receiving the benchmark reports, participants expressed more interest in comparing practices with peers. Because we had promised to maintain confidentiality we never identified participants, but through their own initiative, some participants identified and reached out to others with whom they had established relation- 
ships. Given this interest, and the potential benefits of these direct interactions, we encourage future studies to adopt a focus group format that facilitates peer sharing and allows a better understanding of the specific constraints and opportunities of others in the peer group.

There is conflicting information about the degree to which external influences motivate farmers to improve practices (Jansen et al., 2010; Main et al., 2012; Bruijnis et al., 2013; Russell and Bewley, 2013). Valeeva et al. (2007) found that Dutch dairy farmers were motivated more by internal factors than by esteem from their colleagues. In contrast, Swinkels et al. (2015) found that approval by their peers influenced Dutch dairy farmers' decisions to reduce mastitis. Similar to Jansen et al. (2010), farmers in our study varied in the extent that peers were used as an information source on calf management, suggesting that benchmarking may encourage some but not others to reach out to peers.

In a survey of Kentucky dairy farmers, Russell and Bewley (2013) found that peer influence was less important to decision-making than financial performance and employee satisfaction. However, these authors elsewhere suggested that lack of exposure to peer influence, such as benchmarking, may affect farmers' opinions of its importance (Russell and Bewley, 2011). Considering our study's finding of favorable attitudes toward benchmarking, and the positive reception to the data, we conclude that benchmarking can be useful in facilitating a more data-driven approach to farm management.

More work is needed to determine the number and frequency of reports needed to motivate and sustain positive changes. One potential problem with providing many reports is that this may leave some farmers feeling overwhelmed with data. This concern was not voiced by participants in the current study, suggesting that further reports could have been helpful. Indeed, given the number and complexity of factors affecting both the success of colostrum feeding and calf growth, we suggest that farmers would benefit from routine reporting that allows them to track success and identify problems at an early stage.

A key feature of our study design was the cooperation of the herd veterinarian in delivering the reports. The relationship between the farmer and the herd veterinarian likely plays an important role in determining how animals are cared for on the farm. This issue will be addressed in a future paper.

Moriarty (2011) argued that competitive survival is the key motivator for why participants improve through benchmarking. In our study, benchmarking was more related to pride in performance rather than outperforming competitors. The extent to which benchmarking can motivate farmers will likely depend on their perception of the relevance of the indicators benchmarked.
For some, benchmarking can be used to introduce new outcomes of interest. For others, if they do not identify practices as fitting their management strategies, then the value of benchmarking these practices is diminished (Moriarty, 2011); this was evident in the current study for farmers who did not view high growth rates for calves as a goal for their farm. As noted in Theme 2, there was also a concern with adopting management practices based on benchmark performance without knowing if one's own farm was comparable to the other farms. One suggestion for follow-up research would be to ask farmers to specify their goals in advance (allowing them to benchmark performance against their own goals).

Mee (2013) argued that poor outcomes for dairy calves are due in part to the low priority given to them. However, the participants in our study indicated that the calves were valued, suggesting that problems in calf health and growth may reflect poor assessment methods rather than a lack of interest. Before participating in this study, none of the farms routinely assessed passive transfer of colostral antibodies or calf growth. That farmers do not routinely collect key performance indicators on calves stands in contrast with the other datadriven features characteristic of modern dairy farming, such as reproduction (LeBlanc et al., 2006). Our work suggests that providing routine access to data on calves would be welcomed by many farmers and integrated into decision-making practices.

\section{Interpreting this Study}

Context is key to the critical realist approach (Maxwell, 2012); therefore, the specific context within which farmers made changes to their calf management should be considered when interpreting these research findings. For example, in this study, there was no fee associated with data collection or report delivery; results might have differed if farmers were required to pay for this service.

Social desirability response bias, or the projection of a positive self-image, is inherent in social science research, particularly if respondents are not comfortable sharing their feelings and thoughts with the interviewer (Polkinghorne, 2007). We acknowledge that this bias is a risk in the current work but argue that the use of multiple visits to establish a rapport, repeated interviews to corroborate information, and the time between interviews to allow for participant reflection all helped to minimize bias (Polkinghorne, 2007).

We used a qualitative approach to gain a deeper understanding of farmers' experiences during a benchmark study and identify factors that explain farmer motivation to improve calf management. We believe 
our results provide insight into farmer decisions that can inform future studies and extension efforts; farmer decisions about calf care are complex, involving economic and personal values, and pragmatism in evaluating a new technology, and require in-depth exploration of how these all manifest in decision-making. Our rich description of the context of our study and the use of first-hand accounts to demonstrate the farmers' point of view may help enhance the transferability of our results (see Houghton et al., 2013) by improving our understanding of how different individuals respond to benchmarking. We encourage the use of qualitative methods to better understand how attempts to promote management changes on farm succeed or fail.

Our results are based on a purposive sample of participants and as such do not seek to represent the views of all dairy farmers. Future studies using other methods such as surveys may provide a better understanding of how representative these phenomena are in larger populations of farmers. Indeed, future research may consider mixing qualitative and quantitative methods to make stronger claims about farmer experiences (Kristensen and Jakobsen, 2011).

\section{CONCLUSIONS}

Access to data has intrinsic and instrumental value for farmers and is linked with the overall value farmers place on their calves. Benchmarking helps shift social norms around calf management and tap into social networks to identify ways of improving calf care.

\section{ACKNOWLEDGMENTS}

We thank fellow Animal Welfare Program members, especially Beth Ventura for her help in planning the study, Dax Atkinson for his collaboration in data collection, and Katie Koralesky and Nicole Gillis for their help with the data analysis. We also thank Hannah Wittman (University of British Columbia) for her comments and suggestions on a previous version of this manuscript. Funding for Christine Sumner was provided by the University of British Columbia's 4YF doctoral fellowship program. This research was made possible by the funding for the biological outcomes (described in Atkinson et al., 2017) from NSERC's Industrial Research Chair program, with industry contributions from the Dairy Farmers of Canada (Ottawa, ON, Canada), British Columbia Dairy Association (Burnaby, BC Canada), Westgen Endowment Fund (Milner, BC, Canada), Intervet Canada Corporation (Kirkland, QC, Canada), Novus International Inc. (Oakville, ON, Canada), Zoetis (Kirkland, QC, Canada), BC Cattle Industry Development Fund (Kamloops, BC, Canada),
Alberta Milk (Edmonton, AB, Canada), Valacta (St. Anne-de-Bellevue, QC, Canada), and CanWest DHI (Guelph, ON, Canada).

\section{REFERENCES}

Ajzen, I. 1991. The theory of planned behavior. Organ. Behav. Hum. Decis. Process. 50:179-211. https://doi.org/10.1016/0749 -5978(91)90020-T.

Anderson, K., and R. McAdam. 2004. A critique of benchmarking and performance measurement: lead or lag? Benchmarking Int. J. 11:1463-1483. https://doi.org/10.1108/14635770410557708.

Armitage, C. J., and M. Connor. 2001. Efficacy of the theory of planned behavior: A meta-analytic review. Br. J. Soc. Psychol. 40:471-499.

Atkinson, D. J., M. A. G. von Keyserlingk, and D. M. Weary. 2017. Benchmarking passive transfer of immunity and growth in dairy calves. J. Dairy Sci. 100:3773-3782. https://doi.org/10.3168/jds 2016-11800.

Beam, A. L., J. E. Lombard, C. A. Kopral, L. P. Garber, A. L. Winter, J. A. Hicks, and J. L. Schlater. 2009. Prevalence of failure of passive transfer of immunity in newborn heifer calves and associated management practices on US dairy operations. J. Dairy Sci. 92:3973-3980. https://doi.org/10.3168/jds.2009-2225.

Becker, J., M. Reist, K. Friedli, D. Strabel, M. Wüthrich, and A. Steiner. 2013. Current attitudes of bovine practitioners, claw-trimmers and farmers in Switzerland to pain and painful interventions in the feet in dairy cattle. Vet. J. 196:467. https://doi.org/10.1016/ j.tvjl.2012.12.021.

Borges, J. A. R., A. G. J. M. Oude Lansik, C. M. Ribeiro, and V. Lutke. 2014. Understanding farmers' intention to adopt improved natural grassland using the theory of planned behavior. Livest. Sci. 169:163-174. https://doi.org/10.1016/j.livsci.2014.09.014.

Brennan, M. L., N. Wright, W. Wapenaar, S. Jarratt, P. HobsonWest, I. F. Richens, J. Kaler, H. Buchanan, J. N. Huxley, and H. M. O'Connor. 2016. Exploring attitudes and beliefs towards implementing cattle disease prevention and control measures: A qualitative study with dairy farmers in Great Britain. Animals (Basel) 6:61. https://doi.org/10.3390/ani6100061.

Bruijnis, M., H. Hogeveen, C. Garforth, and E. Stassen. 2013. Dairy farmers' attitudes and intentions towards improving dairy cow foot health. Livest. Sci. 155:103-113. https://doi.org/10.1016/j.livsci .2013.04.005.

Burton, R. J. F. 2004. Reconceptualising the 'behavioral approach' in agricultural studies: A social-psychological perspective. J. Rural Stud. 20:359-371. https://doi.org/10.1016/j.jrurstud.2003.12.001.

Chapinal, N., A. K. Barrientos, M. A. G. von Keyserlingk, E. Galo, and D. M. Weary. 2013. Herd-level risk factors for lameness in freestall farms in the northeastern United States and California. J. Dairy Sci. 96:318-328. https://doi.org/10.3168/jds.2012-5940.

de Lauwere, C., M. van Asseldonk, J. van t'Riet, J. de Hoop, and E. ten Pierick. 2012. Understanding farmers' decision with regard to animal welfare: The case of changing to group housing for pregnant sows. Livest. Sci. 143:151-161. https://doi.org/10.1016/j .livsci.2011.09.007.

Fong, S. W., E. W. L. Cheng, and D. C. K. Ho. 1998. Benchmarking: A general reading for management. Manage. Decis. 36:407-418. https://doi.org/10.1108/00251749810223646.

Glasman, L. R., and D. Albarracín. 2006. Forming attitudes that predict future behavior: A meta-analysis of the attitude-behavior relation. Psychol. Bull. 132:778-822. https://doi.org/10.1037/0033 -2909.132 .5 .778 .

Goh, E. 2009. Public education and parents: Eliciting salient beliefs using the theory of planned behavior as qualitative framework. Int. Rev. Public Nonprofit Mark. 6:99-108. https://doi.org/10.1007/ s12208-009-0024-y.

Heinrichs, A. J., and N. E. Kiernan. 1994. Initial results of a statewide extension program in calf and heifer management in Pennsylvania. J. Dairy Sci. 77:338-342. 
Hötzel, M. J., and J. N. Sneddon. 2013. The role of extensionists in Santa Catarina, Brazil, in the adoption of providing pain relief to calves for dehorning. J. Dairy Sci. 96:1535-1548. https://doi.org/ 10.3168/jds.2012-5780.

Houghton, C., D. Casey, D. Shaw, and K. Murphy. 2013. Rigour in qualitative case-study research. Nurse Res. 20:12-17. https://doi .org/10.7748/nr2013.03.20.4.12.e326.

Jansen, J., C. D. M. Steuten, R. J. Renes, N. Aarts, and T. J. G. M. Lam. 2010. Debunking the myth of the hard-to-reach farmer: Effective communication on udder health. J. Dairy Sci. 93:12961306. https://doi.org/10.3168/jds.2009-2794.

Jansen, J., B. H. P. van den Borne, R. J. Renes, G. van Schaik, T. J. G. M. Lam, and C. Leeuwis. 2009. Explaining mastitis incidence in Dutch dairy farming: The influence of farmers' attitudes and behaviors. Prev. Vet. Med. 92:210-223. https://doi.org/10.1016/j prevetmed.2009.08.015.

Kauppinen, T., A. Vainio, A. Valros, H. Rita, and K. Vesla. 2010. Improving animal welfare: qualitative and quantitative methodology in the study of farmers' attitudes. Anim. Welf. 19:523-536.

Kehoe, S. I., B. M. Jayarao, and A. J. Heinrichs. 2007. A survey of bovine colostrum composition and colostrum management practices on Pennsylvania dairy farms. J. Dairy Sci. 90:4108-4116. https:// doi.org/10.3168/jds.2007-0040.

Khade, A. S., and S. K. Metlen. 1996. An application of benchmarking in the dairy industry. Benchmarking Int. J. 3:34-41. https://doi .org/10.1108/14635779610153354.

Khan, M. A., D. M. Weary, and M. A. G. von Keyserlingk. 2011. Invited review: Effects of milk ration on solid feed intake, weaning, and performance in dairy heifers. J. Dairy Sci. 94:1071-1081. https://doi.org/10.3168/jds.2010-3733.

Kristensen, E., and E. B. Jakobsen. 2011. Challenging the myth of the irrational dairy farmer: understanding decision-making related to herd health. N. Z. Vet. J. 59:1-7.

Leach, K. A., H. R. Whay, C. M. Maggs, Z. E. Barker, E. S. Paul, A. K. Bell, and D. C. J. Main. 2010a. Working towards a reduction in cattle lameness: 1 . Understanding barriers to lameness control on dairy farms. Res. Vet. Sci. 89:311-317. https://doi.org/10.1016/j .rvsc.2010.02.014.

Leach, K. A., H. R. Whay, C. M. Maggs, Z. E. Barker, E. S. Paul, A. K. Bell, and D. C. J. Main. 2010b. Working towards a reduction in cattle lameness: 2. Understanding dairy farmers' motivations. Res. Vet. Sci. 89:318-323. https://doi.org/10.1016/j.rvsc.2010.02.017.

LeBlanc, S. J., K. D. Lissemore, D. F. Kelton, T. F. Duffield, and K. E. Leslie. 2006. Major advances in disease prevention in dairy cattle. J. Dairy Sci. 89:1267-1279. https://doi.org/10.3168/jds.S0022 -0302(06)72195-6.

Magd, H., and A. Curry. 2003. Benchmarking: Achieving best value in public-sector organisations. Benchmarking Int. J. 10:261-286. https://doi.org/10.1108/14635770310477780.
Main, D. C. J., K. A. Leach, Z. E. Barker, A. K. Sedgwick, C. M. Maggs, N. J. Bell, and H. R. Whay. 2012. Evaluating and intervention to reduce lameness in dairy cattle. J. Dairy Sci. 95:2946-2954. https://doi.org/10.3168/jds.2011-4678.

Manicas, P. T. 2006. A Realist Philosophy of Social Science: Explanation and Understanding. Cambridge University Press, Cambridge, UK.

Maxwell, J. A. 2012. A Realist Approach for Qualitative Research. Sage, Thousand Oaks, CA.

Mee, J. F. 2013. Why do so many calves die on modern dairy farms and what can we do about calf welfare in the future? Animals (Basel) 3:1036-1057. https://doi.org/10.3390/ani3041036.

Miles, M. B., A. M. Huberman, and J. Saldaña. 2014. Qualitative Data Analysis: A Methods Sourcebook. 3rd ed. Sage, Thousand Oaks, CA.

Moriarty, J. P. 2011. A theory of benchmarking. Benchmarking Int. J. 18:588-612. https://doi.org/10.1108/14635771111147650.

Polkinghorne, D. E. 2007. Validity issues in narrative research. Qual. Inq. 13:471-486. https://doi.org/10.1177/1077800406297670.

Russell, R. A., and J. M. Bewley. 2011. Producer assessment of dairy extension programming in Kentucky. J. Dairy Sci. 94:2637-2647. https://doi.org/10.3168/jds.2010-3840.

Russell, R. A., and J. M. Bewley. 2013. Characterization of Kentucky dairy producer decision-making behavior. J. Dairy Sci. 96:47514758. https://doi.org/10.3168/jds.2012-6538.

Swinkels, J. M., A. Hilkens, V. Zoche-Golob, V. Krömker, M. Buddiger, J. Jansen, and T. J. G. M. Lam. 2015. Social influences on the duration of antibiotic treatment of clinical mastitis in dairy cows. J. Dairy Sci. 98:2369-2380. https://doi.org/10.3168/jds.2014 $-8488$.

Te Velde, H., N. Aarts, and C. van Woerkum. 2002. Dealing with ambivalence: Farmers' and consumers' perceptions of animal welfare in livestock breeding. J. Agric. Environ. Ethics 15:203-219. https://doi.org/10.1023/A:1015012403331.

Vaarst, M., and J. T. Sørensen. 2009. Danish dairy farmers' perceptions and attitudes related to calf-management in situations of high versus no calf mortality. Prev. Vet. Med. 89:128-133. https:// doi.org/10.1016/j.prevetmed.2009.02.015.

Valeeva, N. I., T. J. G. M. Lam, and H. Hogeveen. 2007. Motivation of dairy farmers to improve mastitis management. J. Dairy Sci. 90:4466-4477. https://doi.org/10.3168/jds.2007-0095.

Windeyer, M. C., K. E. Leslie, S. M. Godden, D. C. Hodgins, K. D. Lissemore, and S. J. LeBlanc. 2014. Factors associated with morbidity, mortality, and growth of dairy heifer calves up to 3 months of age. Prev. Vet. Med. 113:231-240. https://doi.org/10.1016/j .prevetmed.2013.10.019. 